TITLE:

\title{
Growth characteristics of AlN on sapphire substrates by modified migration-enhanced epitaxy
}

$\operatorname{AUTHOR}(S)$ :

Banal, Ryan G.; Funato, Mitsuru; Kawakami, Yoichi

CITATION:

Banal, Ryan G. ...[et al]. Growth characteristics of AlN on sapphire substrates by modified migration-enhanced epitaxy. Journal of Crystal Growth 2009, 311(10): 2834-2836

ISSUE DATE:

2009-05-01

URL:

http://hdl.handle.net/2433/123387

RIGHT:

Copyright (c) 2009 Elsevier B.V.; This is not the published version. Please cite only the published version.; この論文は出版社版でありません。引 用の際には出版社版をご確認ご利用ください。 


\title{
Growth characteristics of AIN on Sapphire Substrates by Modified Migration Enhanced Epitaxy
}

\author{
Ryan G. Banal, Mitsuru Funato ${ }^{1)}$ and Yoichi Kawakami \\ Department of Electronic Science \& Engineering, Kyoto University, Kyoto 615-8510, Japan
}

We investigated the effect of growth parameters for obtaining high-quality AlN grown directly on sapphire substrates by a hybridized method, derived from simultaneous source supply and conventional migration enhanced epitaxy. At an optimal growth temperature of $1200{ }^{\circ} \mathrm{C}$, AlN was atomically smooth and pit-free, while below and above $1200{ }^{\circ} \mathrm{C}$, AlN was rough and with pits, respectively. Surface morphologies also depended on the V/III ratio. Rough surfaces became atomically smooth but then pits appeared, as the V/III ratio was increased. The crystallinity revealed by x-ray diffraction changed accordingly. The 600-nm-thick AlN grown under the optimal conditions showed x-ray line widths of as narrow as $\sim 43$ and $\sim 250$ arcsec for (0002) and (10 $\overline{1} 2)$ diffractions, respectively.

Keywords: metalorganic vapor phase epitaxy, nitrides, semiconducting III-V materials PACS: 81.15.Gh, 81.05.Ea

\footnotetext{
${ }^{1)}$ Corresponding author: email: funato@kuee.kyoto-u.ac.jp, Phone: +81 75383 2311, Fax: +81 753832312
} 


\section{Introduction Several growth methods have been proposed for AlN with the} ultimate goal of improving the overall quality of this wide bandgap material. However, obtaining an AlN epilayer with low defect-density remains elusive. The absence of thick and defect-free bulk substrates aggravates the problem because heteroepitaxial growth on foreign substrates such as sapphire and $\mathrm{SiC}[1,2]$ generates a high-density of threading dislocations that affect the radiative property of a device [3]. Furthermore, growing AlN epilayers by simultaneous supply of trimethylaluminium (TMA) for group III and $\mathrm{NH}_{3}$ for group $\mathrm{V}$ sources is not recommended because of parasitic reactions [4]. One of the promising growth methods for obtaining high-quality AlN is by alternating supply of either or both TMA and $\mathrm{NH}_{3}$ [5-11]. Unlike the case of GaN where the Ga-N cohesive energy is much lower compared to Al-N, a significant reduction in migration of group-III adatoms happens for AlN growth. Therefore the reasons for the separate supply of source gases are the enhancement of Al-adatom migration and at the same time, reduction of parasitic reactions. Recently, we showed experimental evidences that alternating supply of the source precursors can enhance the migration of $\mathrm{Al}$ adatoms and this enhancement is pronounced especially during the initial nucleation stage [11]. Moreover, we also reported that the migration degree can be tailored or controlled to modify the nucleation mechanism thereby achieving an epilayer with a low threading dislocation density and atomically smooth surface. This method is modified migration enhanced epitaxy (MEE) hybridized from conventional MEE and simultaneous source-supply such that the latter is inserted inbetween the former. In this paper, we focus on the effect of growth parameters such as growth temperature and flux ratio on the modified MEE of AlN. 


\section{Experimental AlN epilayers were grown directly on sapphire (0001)} substrates by metalorganic vapor phase epitaxy. Source gases were $\mathrm{NH}_{3}$ and TMA for $\mathrm{N}$ and $\mathrm{Al}$, respectively, and $\mathrm{H}_{2}$ was the carrier gas. The growth temperature and V/III ratio were varied while maintaining the total pressure at 76 Torr. The effect of V/III was studied by changing only the flow rate of $\mathrm{NH}_{3}(490-1161 \mu \mathrm{mol} / \mathrm{min})$ while the TMA flow rate was kept at $4.11 \mu \mathrm{mol} / \mathrm{min}$. Prior to AlN growth, as-received substrates were thermally etched in $\mathrm{H}_{2}$ gas for about 10 minutes at $122{ }^{\circ} \mathrm{C}$. Then the temperature was brought down to 1190 $1210^{\circ} \mathrm{C}$, where the growth of AlN was performed by modified MEE, which was detailed in Ref. [11]. The flow sequence is shown in Fig. 1. For 850 cycles, approximately 600-nmthick AlN epilayer was obtained.

The AlN thicknesses were estimated by an interferometer and the surface morphology was analyzed by atomic force microscopy (AFM). High-resolution X-ray diffraction (HRXRD) rocking curve measurements for the symmetric (0002) and asymmetric (1012) reflections were conducted for structural quality comparison. The asymmetric measurements were in the skew geometry.

3 Results and analysis The effect of growth temperature $\left(T_{g}\right)$ on the quality of AlN is first discussed. The V/III ratio was 174, which is the optimized value as described below. Figure 2 shows the AFM surface morphologies. The morphology changed from rough to atomically smooth when $T_{g}=1200{ }^{\circ} \mathrm{C}$. Further increase of $T_{g}$ changes the epilayer surface to have pits. These pits are found particularly along the step edge. The surface roughness revealed root-mean-square (RMS) values of $0.16,0.12$, and $\sim 0.23 \mathrm{~nm}$ as the 
temperature was increased from 1190 to $1210^{\circ} \mathrm{C}$. Moreover, surface quality has been found very sensitive to growth temperature as a slight change of $5^{\circ} \mathrm{C}$ caused significant deterioration of epilayer. This is contrary to a report using simultaneous source-supply method, which showed no clear dependence of crystalline quality on growth temperatures [12].

It is known that the degree of $\mathrm{Al}$ adatom migration is enhanced by the growth temperature aside from alternating source supply. When $T_{g}$ is low, migration is less active thereby an increased number of nucleation sites promotes surface roughening, as evidenced by AlN grown at $T_{g}=1195^{\circ} \mathrm{C}$ (Fig. 2a). On the other hand, when $T_{g}$ is above the optimum, though the degree of migration is enhanced, the shorter mean residence time of adatoms and its easy desorption from the surface could have promoted the generation of those pits. This case happens when $T_{g}>1205^{\circ} \mathrm{C}$. At an optimal $T_{g}$, the sufficient adatom migration enables to achieve a smooth AlN. It is therefore unnecessary to bring $T_{g}$ of AlN near its sublimation point $\left(2000^{\circ} \mathrm{C}\right)$ just to enhance the migration [13], because further increase of $T_{g}$ beyond $1200{ }^{\circ} \mathrm{C}$ only deteriorates the epilayer quality.

The degradation of surface quality is accompanied by deterioration in structural quality as confirmed by HRXRD measurements. Figure 3 shows the full-width at halfmaximum (FWHM) of the asymmetric (101ㄹ) diffraction (Fig. 3a) and the symmetric (0002) diffraction (Fig. 3b). Especially for the $(10 \overline{1} 2)$ plane, the quality drastically changed from 1100 to 250 arcsec, and then to 1150 arcsec as $T_{g}$ is below, at, and above $1200{ }^{\circ} \mathrm{C}$, correspondingly. This is also true for the (0002) plane, but the epilayer quality did not deteriorate as drastically as that in asymmetric (10 $\overline{1} 2)$ plane. 
The V/III ratio was also studied by changing the amount $\mathrm{NH}_{3}$ while keeping the TMA flow rate. Here, $T_{g}$ was always at the optimized temperature of $1200{ }^{\circ} \mathrm{C}$. It was reported that unwanted trimers and higher n-mers with increasing $\mathrm{NH}_{3}$ leads to a decrease of growth rate [14]. Though active $\mathrm{N}$ species would be readily available when $\mathrm{NH}_{3}$ flux is in excess, it is necessary to control its amount in order to achieve a flat and high-quality AlN [15], which was demonstrated by the AFM surface images shown in Fig. 4. While a V/III 174 has realized a defect-free surface (Fig. 4b), further decreasing the V/III ratio roughened the surface (Fig. 4a). A similar result was also observed in Ref. [16]. The insufficient amount of $\mathrm{NH}_{3}$ led to more available $\mathrm{Al}$ adatoms, which remained unreacted due to the less amount of group V sources. Conversely, a greater amount of group V tends to generate pits along the step-edges (Fig. 4c-d). This deterioration in the quality of AlN was further confirmed by the results of symmetric and asymmetric HRXRD as shown in Fig. 5.

To discuss the mechanism of the observed growth characteristics, it is interesting to compare the surface morphologies displayed in Figs. 2 and 4. Thus, it is found that lower $T_{g}$ and V/III roughened the surfaces while higher $T_{g}$ and V/III induced pits. These observations suggest that effective V/III ratio, which is the ratio between the number of $\mathrm{Al}$ adatoms and $\mathrm{N}$ species that actually contribute to the growth, could be the critical growth parameter. That is, under lower $T_{g}$ or $\mathrm{V} / \mathrm{III}$, the $\mathrm{NH}_{3}$ decomposition is not sufficient to provide the optimal number of active $\mathrm{N}$ species for the AlN growth, while at higher $T_{g}$ or V/III, excess $\mathrm{N}$ species enhance pit formation. Because $T_{g}$ and V/III are thus related to each other, in order to maintain the optimal number of active $\mathrm{N}$ species, higher $T_{g}$ must be employed when lower V/III is used, and vice versa. In this study, we found that the structural 
properties depend strongly on the growth conditions such as temperatures and V/III ratios. On the other hand, successful growth of AlN at a much higher temperature of $1400^{\circ} \mathrm{C}$ was reported [17]. At this stage, it has yet to be clarified as to why the observed growth characteristics were so sensitive to the growth conditions.

Based on the above observations, the growth process was finally optimized using a growth temperature of $1200{ }^{\circ} \mathrm{C}$ and V/III ratio of 174 , and an atomically smooth AlN epilayer was successfully achieved as shown in Figs. 2b or 4b. This epilayer has a RMS roughness of $0.12 \mathrm{~nm}\left(5 \times 5 \mu \mathrm{m}^{2}\right)$. The FWHM of their (0002) and $(10 \overline{1} 2)$ planes $\omega$-scans were 43 and 250 arcsec, respectively. From the FWHM of the (0002) diffraction, which corresponds to the tilt component, the screw dislocation density $\left(N_{\mathrm{s}}\right)$ was calculated to be $\sim 4.0 \times 10^{6} \mathrm{~cm}^{-2}$, using the an equation of $N_{\mathrm{s}}=\operatorname{tilt}^{2} /\left(4.35\left|\boldsymbol{b}_{\mathrm{s}}\right|^{2}\right)$, where $\boldsymbol{b}_{\mathrm{s}}$ is the Burgers vector equal to $<0001>$ [18]. On the other hand, the twist component was estimated to be 365 arcsec from the FWHMs of (0002) and (10 $\overline{1} 2)$ diffractions, assuming that x-ray diffraction profiles were approximated by Gaussian curves and that there was no interaction between tilt and twist [19]. Then, the density of randomly distributed edge dislocations $\left(N_{\mathrm{e}}\right)$ given by $N_{\mathrm{e}}=$ twist $^{2} /\left(4.35\left|\boldsymbol{b}_{\mathrm{e}}\right|^{2}\right)$ where $\boldsymbol{b}_{\mathrm{s}}$ is the Burgers vector equal to $<11 \overline{2} 0>/ 3$, was evaluated to be $7.4 \times 10^{8} \mathrm{~cm}^{-2}$. For the polarity test, samples were dipped in $20 \% \mathrm{KOH}$ solution at $70^{\circ} \mathrm{C}$ for 3 minutes. Etch pits appeared, but the area without etch pits were not etched at all, thus revealing the Al-polarity of modified-MEE-grown AlN [20].

4 Conclusion In summary, the surface morphology and crystalline quality of directly-grown AlN on sapphire substrates by modified MEE changed with growth 
temperature and V/IIII ratio. Optimization of these parameters led to a superior-quality AlN as confirmed by its smooth and atomically flat surface, smaller XRD linewidths both for symmetric and asymmetric planes. 


\section{References}

[1] T. Shibata, K. Asai, S, Sumiya, M. Mouri, M. Tanaka, O. Oda, H. Katsukawa, H. Miyake, and K. Hiramatsu, Phys. Stat. Sol. (c) 0, 2023 (2003).

[2] S. Yamada, J. Kato, S. Tanaka, I. Suemune, A. Avramescu, Y. Aoyagi, N. Teraguchi, and A. Suzuki, Appl. Phys. Lett. 78, 3612 (2001).

[3] J.F. Kaeding, Y. Wu, T. Fujii, R. Sharma, P.T. Fini, J.S. Speck, and S. Nakamura, J. Cryst. Growth 272, 257 (2004).

[4] D.G. Zhao, J.J. Zhu, D.S. Jiang, Hui Yang, J.W. Liang, X.Y. Li and H.M. Gong, J. Cryst. Growth 289, 72 (2006).

[5] M. Kurimoto, T. Nakada, Y. Ishihara, M. Shibata, T. Honda, and H. Kawanishi, Jpn. J. Appl. Phys. 38, L551 (1999).

[6] M. Hiroki and N. Kobayashi, Jpn. J. Appl. Phys. 42, 2305 (2003).

[7] V. Adivarahan, W.H. Sun, A. Chitnis, M. Shatalov, S. Wu, H.P. Maruska, and M.A. Khan, Appl. Phys. Lett. 85, 2175 (2004).

[8] M. Takeuchi, H. Shimizu, R. Kajitani, K. Kawasaki, Y. Kumagai, A. Koukitu, and Y. Aoyagi, J. Cryst. Growth 298, 336 (2007). M. Takeuchi, S. Ooishi, T. Ohtsuka, T. Maegawa, T. Koyama, S.F. Chichibu, and Y. Aogi, Appl. Phys. Express, 1, 021102 (2008).

[9] H. Hirayama, T. Yatabe, N. Noguchi, T. Ohashi, and N. Kamata, Appl. Phys. Lett. 91, 071901 (2007).

[10] J. P. Zhang, M.A. Khan, H. M. Wang, W.H. Sun, V. Adivarahan, S. Wu, A. Chitnis, C. Q. Chen, M. Shatalov, E. Koukstis, J. W. Yang, and M. Asif Khan, J. Elec. Mater. 32, 364 (2003).

[11] R.G. Banal, M. Funato and Y. Kawakami, Appl. Phys. Lett. 92, 241905 (2008).

[12] Y.A. Xi, K.X. Chen, F. Mont, J.K. Kim, E.F. Schubert, C. Wetzel, W. Liu, X. Li and J.A. Smart, J. Elec. Mater. 36, 533 (2007).

[13] Q. Paduano and D. Weyburne, Jpn. J. Appl. Phys. 42 (2003) 1591.

[14] T. G. Mihopoulos, V. Gupta and K. F. Jensen, J. Cryst. Growth 195 (1998) 733.

[15] A.V. Lobanova, K.M. Mazaev, R.A. Talalaev, M. Leys, S. Boeykens, K. Cheng and S. Degroote, J. Cryst. Growth 287 (2006) 601. 
[16] S.B. Thapa, C. Kirchner, F. Scholz, G.M. Prinz, K. Thonke, R. Sauer, A. Chuvilin, J. Biskupek, U. Kaiser, and D. Hofstetter, J. Cryst. Growth 298 (2007) 383.

[17] K. Balakrishnan, A. Bandoh, M. Iwaya, S. Kamiyama, H. Amano, and I. Akasaki, Jpn. J. Appl. Phys. 46, (2007) L307.

[18] T. Metzger, R. Höpler, E. Born, O. Ambacher, M. Stutzmann, R. Stömmer, M. Schuster, H. Göbel, S. Christiansen, M. Albrechit, and H. P. Strunk, Philos. Mag. A 77, (1998) 1013, and references therein.

[19] V. Srikant, J. S. Speck, and D. R. Clarke, J. Appl. Phys. 82 (1997) 4286.

[20] D. Zhuang, J. H. Edgar, L. Liu, B. Liu, L. Walker, MRS Int. J. Nitride Semicond. Res. 7 (2001) 4. 


\section{Figure captions}

Fig. 1

Flow pattern of modified MEE. The 3s/cycle is composed of 1s initial supply of $\mathrm{NH}_{3}$ followed by 1s of simultaneous supply of $\mathrm{NH}_{3}$ and TMA and lastly, 1s of TMA.

Fig. 2

Surface AFM images of AIN grown at (a) 1195, (b) 1200 (optimal), (c) 1205, and (d) $1210{ }^{\circ} \mathrm{C}$. The surface is rough at $1195{ }^{\circ} \mathrm{C}$ (a), atomically flat at $1200{ }^{\circ} \mathrm{C}(\mathrm{b})$, and with pits above $1205^{\circ} \mathrm{C}$ (c and d). AlN epilayers were grown using V/III = 174.

Fig. 3

Variation of XRD FWHM of symmetric (0002) and asymmetric (10 $\overline{1} 2)$ planes due to $T_{g}$. The structural is best at $T_{g}=1200{ }^{\circ} \mathrm{C}$. The epilayers were grown using V/III $=174$.

Fig. 4

Surface AFM images of AlN grown under V/III ratios of (a) 119, (b) 174, (c) 228, and (d) 282. The rough surface with V/III = 119 (a) became atomically flat with V/III = 174 (b), but pits appeared with further increase of the V/III ratio above 228 (c and d). $T_{g}$ was $1200{ }^{\circ} \mathrm{C}$.

\section{Fig. 5}

Variation of XRD FWHM of symmetric (0002) and asymmetric (10 $\overline{1} 2)$ planes due to the V/III ratio. The structural quality is best at V/III $=174 . T_{g}$ was $1200{ }^{\circ} \mathrm{C}$. 


\section{Simultaneous}

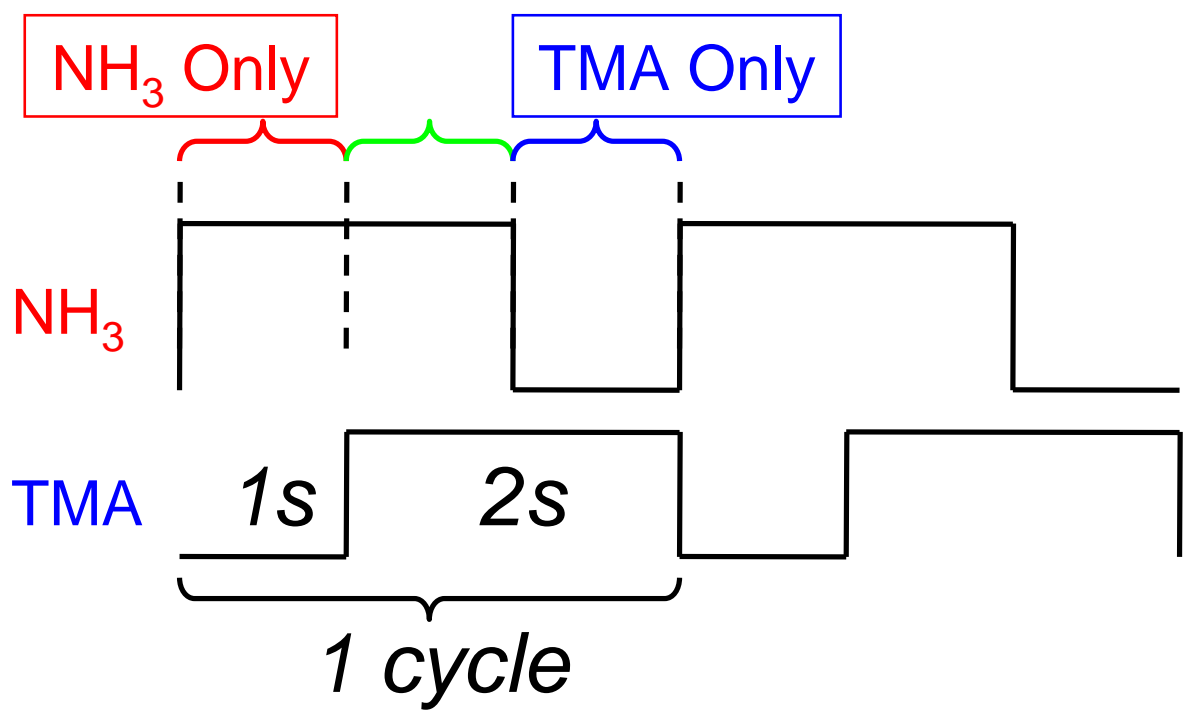

Fig.1 R. Banal et al. 


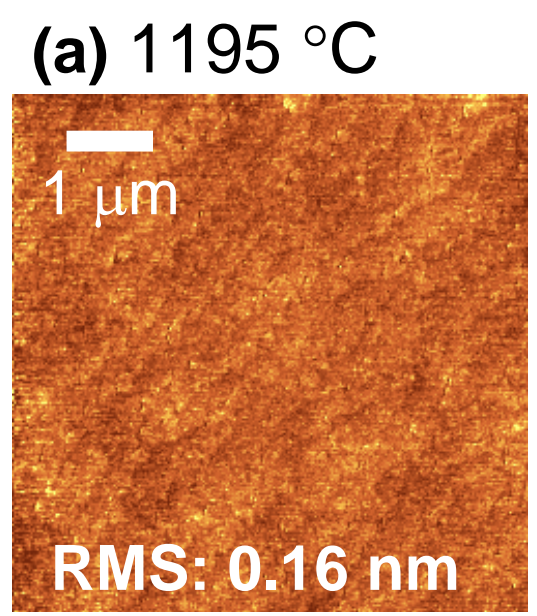

(b) $1200{ }^{\circ} \mathrm{C}$

(c) $1205^{\circ} \mathrm{C}$

(d) $1210^{\circ} \mathrm{C}$

$0.22 \mathrm{~nm}$
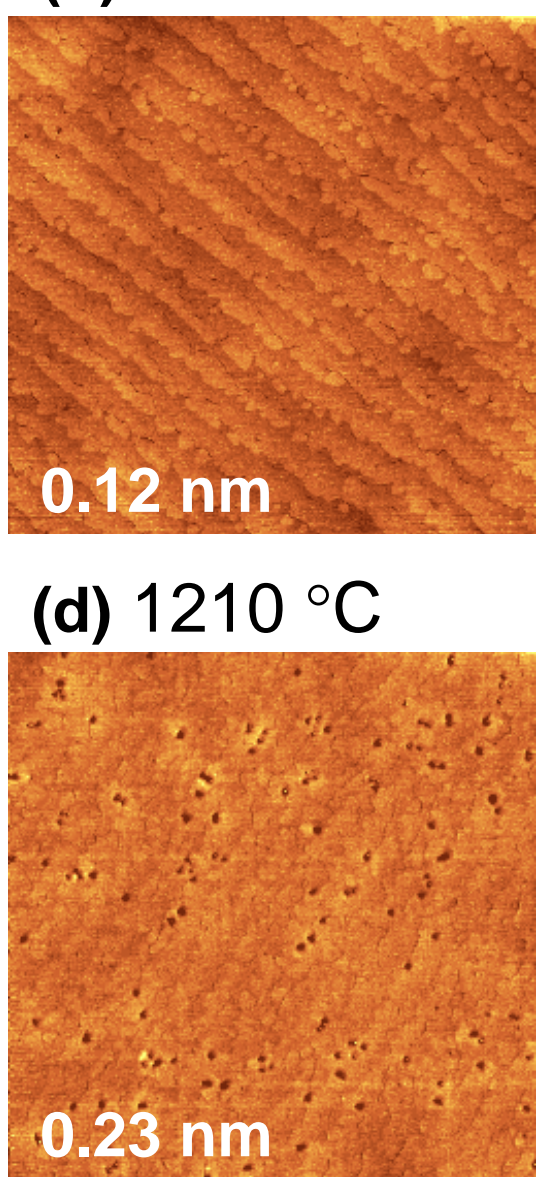

Fig.2 R. Banal et al. 


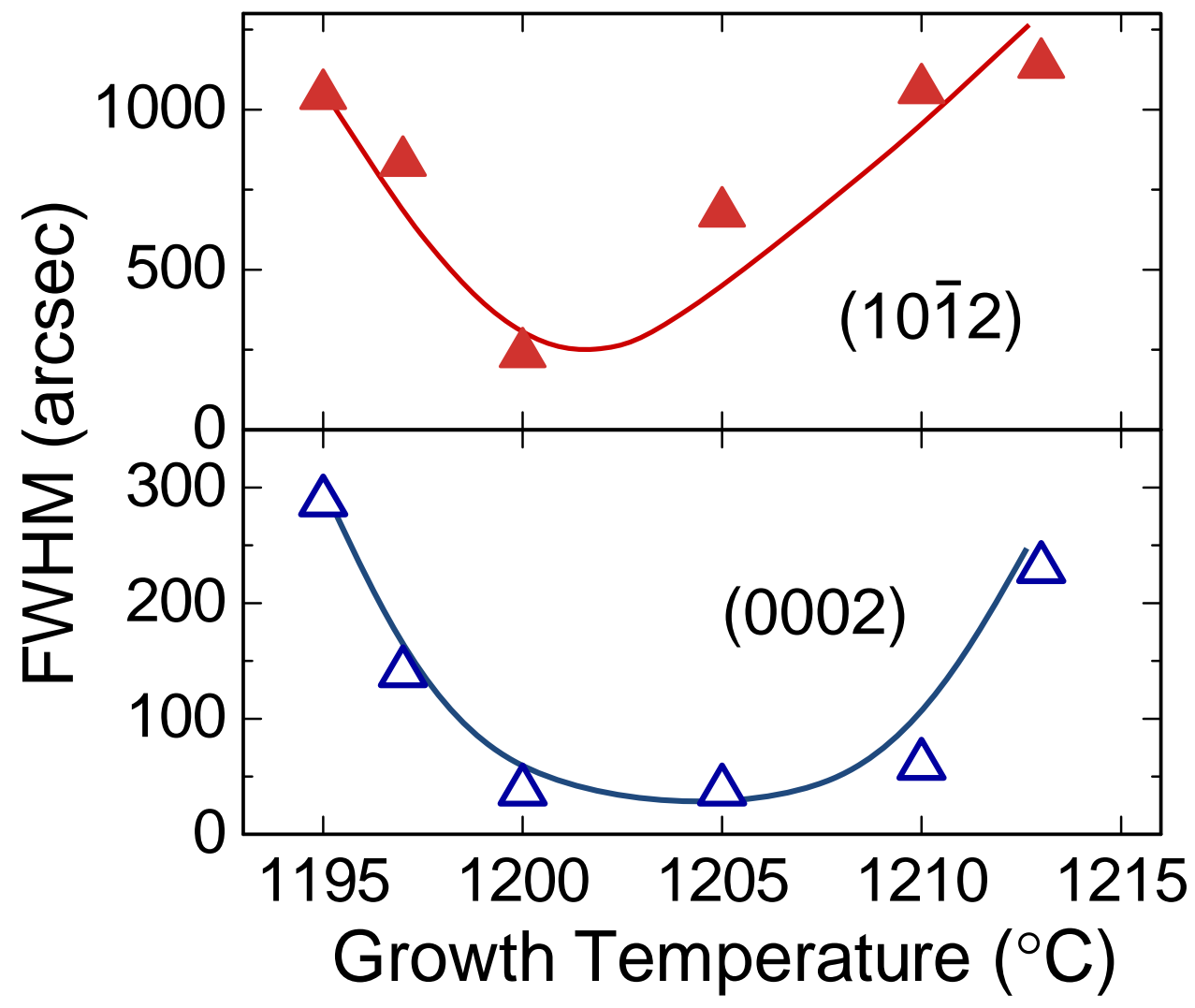

Fig.3 R. Banal et al. 


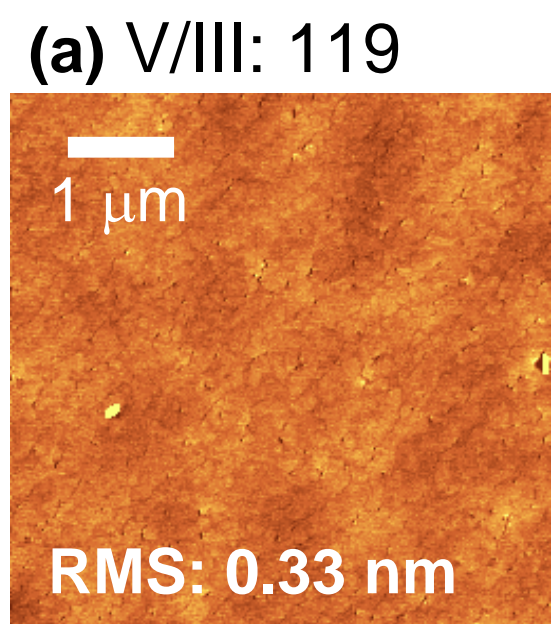

(b) V/III: 174

(c) V/III: 228

(d) V/III: 282

$0.24 \mathrm{nim}$
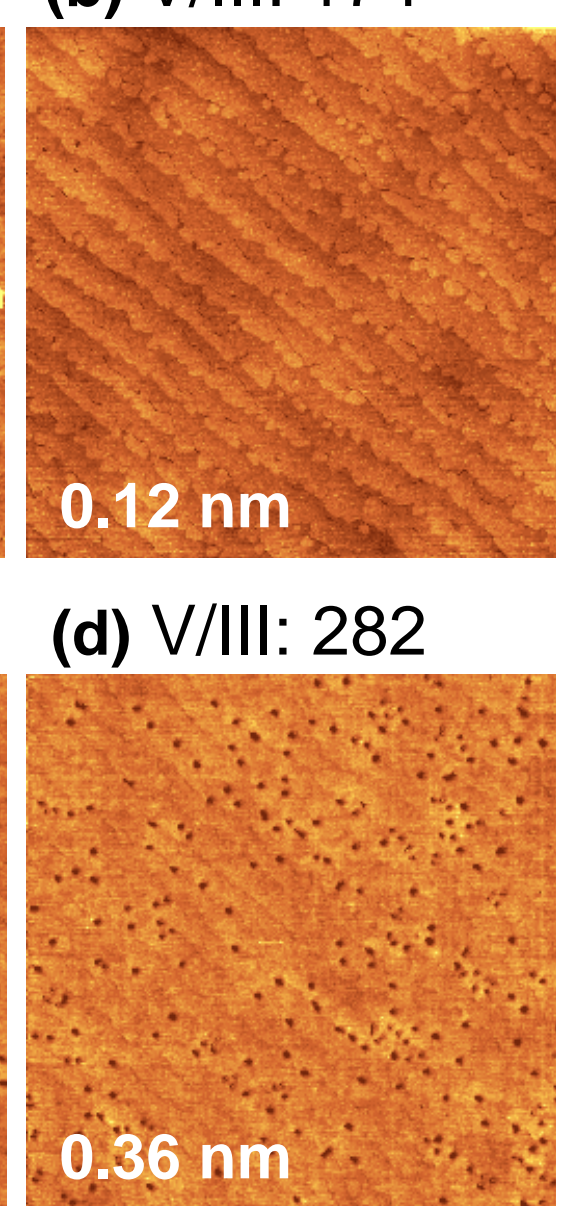

Fig.4 R. Banal et al. 


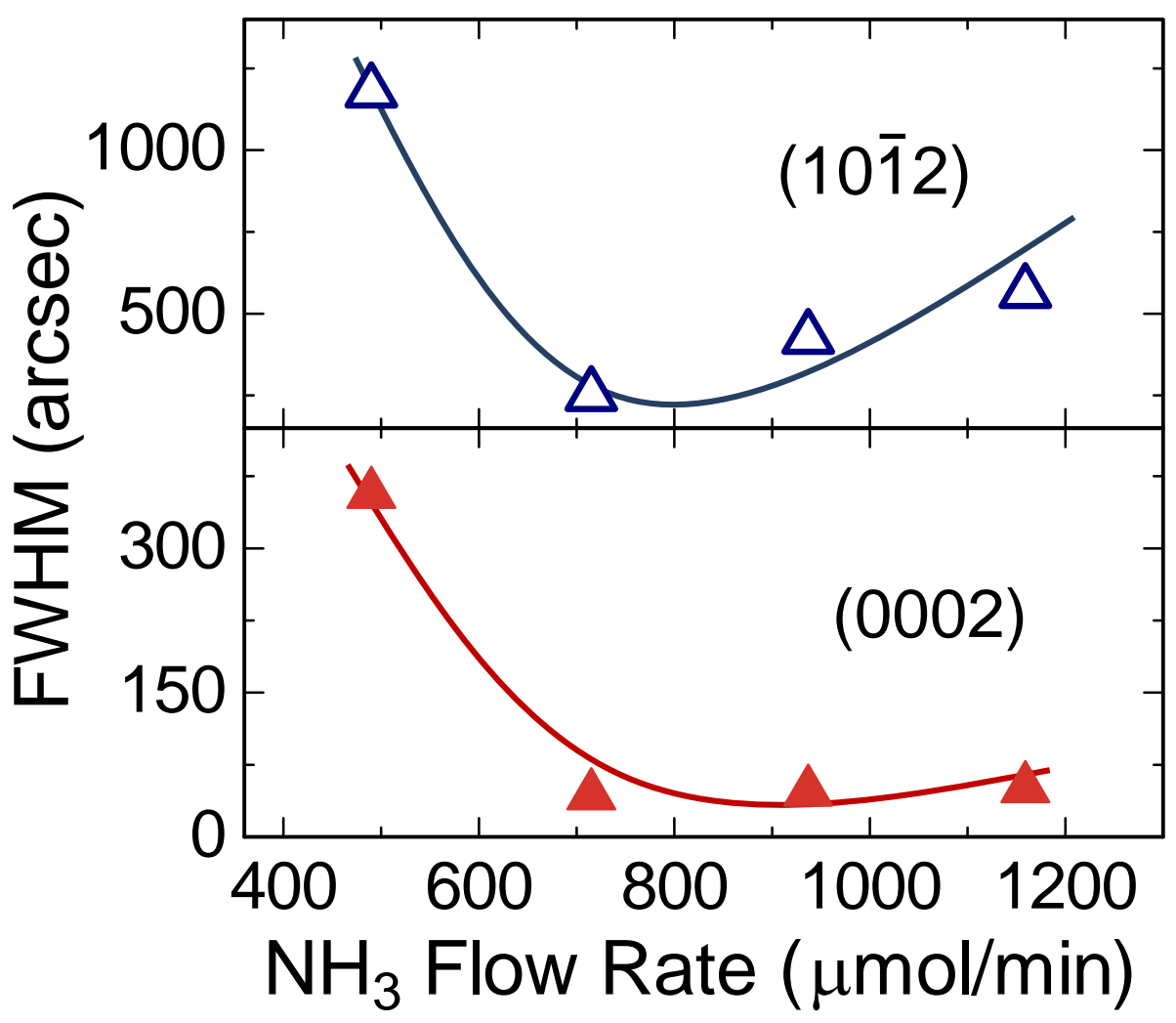

Fig.5 R. Banal et al. 